\title{
Assessment of Acute Episodes in Chronic Stable Angina: A Clinical-Laboratory Approach to the Use of the Coronary Vasodilator Propatyl Nitrate
}

\author{
Gerson Goldwasser'1, Renato Kaufman², Carlos Pereira Nunes ${ }^{3}$, Alexandre Hid' \\ Stephanie Wrobel Goldberg 4 , Alessandra Santos ${ }^{3}$, Lisa Oliveira ${ }^{3}$, \\ Adenilson de Souza da Fonseca ${ }^{3}$, Mauro Geller ${ }^{3}$ \\ ${ }^{1}$ Souza Marques Medical School, Rio de Janeiro, Brazil \\ ${ }^{2}$ Universidade Estadual do Rio de Janeiro, Rio de Janeiro, Brazil \\ ${ }^{3}$ UNIFESO Medical School, Teresópolis, Brazil \\ ${ }^{4}$ Washington University School of Medicine, St. Louis, MO, USA \\ Email: gersongold@globo.com, renatokaufman@gmail.com, carlos.nunes@globo.com, a_hid@bol.com.br, \\ stephwg@gmail.com, alessandraalsantos@gmail.com, lisa.j.brauer@gmail.com, adnfonseca@yahoo.com.br, \\ maurogeller@gmail.com
}

Received 20 May 2016; accepted 23 July 2016; published 26 July 2016

Copyright (C) 2016 by authors and Scientific Research Publishing Inc.

This work is licensed under the Creative Commons Attribution International License (CC BY). http://creativecommons.org/licenses/by/4.0/

(c) (i) Open Access

\section{Abstract}

Background/Objectives: Propatyl nitrate is a coronary vasodilator with immediate and prolonged action, indicated in the treatment and prevention of acute angina pectoris episodes. Methods: This was an open, self-paired comparative study performed at UNIFESO Medical School evaluating the clinical and laboratory results of treatment with propatyl nitrate in patients with chronic stable angina pectoris. Subjects received $10 \mathrm{mg}$ of propatyl nitrate, at the dose of three sublingual tablets per day, to be taken at 8:00 A.M., 2:00 P.M., and 8:00 P.M. Subjects returned to the study center after 15 days of treatment for Visit 2 assessments, and at the end of the 30-day treatment period (Visit 3). Results: A total of 200 subjects were included in the study. There was a statistically significant reduction in blood pressure $(p<0.0001)$ and heart rate $(p=0.0001)$, but no change in respiratory rate $(p=0.23)$. Laboratory results did not vary throughout the treatment period. There was no significant change from pretreatment in the SAQ Physical Limitation scale ( $p=$ 0.7415). The Angina Stability, Angina Frequency, and Treatment Satisfaction, and Quality of Life scales showed a significant improvement from pretreatment $(p<0.0001)$. Adverse events were observed among 41 subjects at Visit 2 and 35 subjects at Visit 3. Conclusions: Propatyl nitrate was safe and effective in treating chronic stable angina pectoris over the course of the 30-day treatment period. Treatment with propatyl nitrate increased angina stability and reduced angina fre- 
quency while increasing treatment satisfaction and quality of life in the patient population evaluated.

\title{
Keywords
}

\author{
Propatyl Nitrate, Stable Chronic Angina Pectoris, Seattle Angina Questionnaire
}

\section{Introduction}

Coronary artery disease is a prevalent health condition worldwide, affecting both developed and underdeveloped nations. In Brazil, cardiovascular illnesses are responsible for 34\% of deaths, of which $1 / 3$ are by diseases of the coronary arteries. Diseases of the circulatory system are in first place among causes of hospitalization in Brazil, and myocardial infarction, heart failure, and stroke are among the diseases most commonly leading to death [1].

Chronic stable angina pectoris is diagnosed in the United States in approximately 500,000 individuals per year, and is related to a decline in quality of life among affected patients and increased physical limitation [2]. This condition is also related to high costs as a result of missed work and medical costs [3]-[6].

Pharmacological angina pectoris therapy aims to provide symptomatic relief and to allow for a progressive improvement of the clinical condition [5]. Pharmacological therapy includes use of aspirin and beta blockers as well as calcium antagonists and nitrates, while more severe cases may require surgical intervention (angioplasty and revascularization) [3].

Propatyl nitrate is a coronary vasodilator that presents immediate and prolonged action. It is indicated in the treatment of acute episodes of angina pectoris, as well as in the prevention of acute angina crises brought on by exercise and in patients with chronic coronary insufficiency [7]-[10]. This drug was first approved under the brand name Etrynit and has been in use since the 1960's when the first studies were performed in Europe investigating the use of propatyl nitrate in patients presenting angina pectoris [11]-[13]. When administered sublingually, propatyl nitrate has a fast onset of action, beginning between 55 and 150 seconds after administration [14] [15], with higher plasma concentrations as compared to oral administration [14].

The primary study objective was to evaluate the clinical and laboratory results of treatment with propatyl nitrate in patients presenting with chronic stable angina pectoris. Secondary study objectives were to assess the efficacy of propatyl nitrate in the treatment of angina pectoris using the Seattle Angina Questionnaire (SAQ) and to assess the safety of this drug through monitoring of laboratory parameters and occurrence, severity, and duration of any adverse events. This is the first large scale study in the Brazilian population using a validated outcome measure (SAQ).

\section{Material \& Methods}

This was an open, self-paired comparative study performed at UNIFESO Medical School. The study protocol and related documents were submitted to and received approval of the Ethical Committee (Approval no. 452.152) and health authorities prior to study startup. After screening and informed consent, eligible subjects (defined as patients of both genders between the ages of 50 and 68 with a clinical diagnosis of chronic stable angina pectoris) were enrolled to treatment.

Pretreatment assessments included demographic data collection as well as assessment of angina episodes, in terms of quality, location, radiation, duration, triggering factors, relief factors, and associated symptoms. Based on these assessments, angina was classified according to the Canadian Cardiovascular Society Grading System for Stable Angina (Grades I-IV) [16]. Subjects presenting Grade IV stable angina at screening were excluded from the study.

The study treatment consisted of sublingual tablets containing $10 \mathrm{mg}$ of propatyl nitrate, at the dose of three sublingual tablets per day, to be taken at 8:00 A.M., 2:00 P.M., and 8:00 P.M. for a period of thirty days. Subjects returned to the study center after 15 days of treatment for Visit 2 assessments, and at the end of the 30-day treatment period (Visit 3). At each study visit, data on compliance, medical history, physical examination, vital signs, and angina evaluation were collected as well as laboratory tests, electrocardiogram, adverse event monitoring and use of concomitant medication. 
In this study, efficacy was evaluated using the Seattle Angina Questionnaire [17] performed at pretreatment and at Visit 3. The SAQ is a validated 19-item self-administered questionnaire that measures five areas of coronary artery disease: physical limitation, anginal stability, anginal frequency, treatment satisfaction, and disease perception. The primary efficacy endpoint was the number of angina episodes presented by each subject during the treatment period. This was assessed by the number of subjects presenting with an improvement of $\geqq 30 \%$ on the SAQ subcategory specific for episodes of angina frequency.

Safety variables included vital signs and physical exam as well as occurrence, intensity, and duration of adverse events recorded during the treatment period, in addition to laboratory tests performed at Pretreatment, Visit 2 and Visit 3. Use of concomitant medications was also monitored throughout the treatment period. At the last study visit, the study investigator assessed overall efficacy (using the 5 SAQ categories) and tolerability (overall patient status and incidence, number, and severity of adverse events) of the study drug as "Very Good", "Good", "Fair", or "Poor".

Sample size calculation of 200 subjects was based on predicted SAQ scores for anginal frequency, with a preversus post-treatment mean difference of 0.3 points, with a standard deviation of 1.0, using a two-tailed test with an alpha of 0.05 and power of $80.4 \%$.

All data were recorded in the clinical research form. Statistical analysis of collected data was performed using GraphPad Prism 5 software. Clinical efficacy and safety were statistically analyzed by comparison of the results of each visit in relation to pretreatment data. For comparisons of categorical variables, the chi-squared or Fishers test was used, and for continuous variables we used either the Student's T test or analysis of variance (ANOVA). SAQ scores were coded and analyzed in accordance with the instructions outlined by the developers of the questionnaire.

\section{Results}

A total of 200 subjects were included in the study, with 102 male subjects (51\%) and 98 female subjects (49\%). Mean patient age was 60.96 years $( \pm 4.447)$. The demographic and pretreatment characteristics are summarized in Table 1. Of the total randomized patients, 79 (39.5\%) presented angina Grade I, while 108 (54\%) presented Grade II, and 13 (6.5\%) presented Grade III angina.

At Visit 2, a total of 16 subjects were removed from the study due to: protocol violation $(n=5)$, adverse event $(n=5)$, lost to follow-up $(n=5)$, withdrawal of consent $(n=1)$. At Visit 3 , a further 9 subjects were removed from the study due to: withdrawal of consent $(n=2)$, lost to follow-up $(n=3)$, adverse event $(n=3)$, adverse event and laboratory test alteration $(\mathrm{n}=1)$.

Vital signs and physical examination results were recorded at pretreatment and at subsequent study visits. The results of these observations are presented in Table 2. While there was an increase in mean weight among patients, the change did not reach statistical significance $(\mathrm{p}=0.342)$, however increase in BMI was statistically significant $(p=0.008)$. There was a statistically significant reduction in both systolic and diastolic blood pressure ( $\mathrm{p}<0.0001$ for both assessments). Heart rate also decreased significantly from Pretreatment to Visit 3 ( $\mathrm{p}=$ $0.0001)$. There was no statistically significant change in respiratory rate among treated subjects during the study $(p=0.23)$. Laboratory and electrocardiogram results did not vary throughout the treatment period.

The SAQ Score results are summarized in Figures 1(a)-(e). There was no statistically significant change from pretreatment in the Physical Limitation scale $(\mathrm{p}=0.7415)$. The Angina Stability scale showed a statistically significant improvement from pretreatment $(p<0.0001)$. There was a statistically significant improvement in the Angina Frequency scale as well as in the Treatment Satisfaction scale statistically significant improvement from pretreatment $(\mathrm{p}<0.0001)$. The improvement in the Quality of Life scale was also statistically significant $(\mathrm{p}<$ $0.0001)$.

A total of 56 subjects presented with adverse events during the treatment period. Adverse events were observed among 41 subjects at Visit 2 and 35 subjects at Visit 3 . The adverse events considered to be related to study drug administration included headache (mild, $n=9$; moderate, $n=5$; severe, $n=1$ ), dizziness (mild, $n=7$ ), bradycardia (mild, $n=4)$, nausea (mild, $n=2)$, severe agitation $(n=1)$, mild agitation $(n=1)$, and mild diarrhea, rubor, and sudoresis ( $\mathrm{n}=1$ for each $\mathrm{AE}$ ).

The results of the assessment of overall efficacy and tolerability performed by the investigator at the end of the study were as follows: for efficacy, the study drug was considered "Very Good" among $46.59 \%$ of the subjects, "Good" among 29.55\%, "Acceptable" among 18.75\%, and "Poor" among 5.11\% of the subjects enrolled 
to treatment. In terms of tolerability, the study drug was considered "Very Good" among $47.73 \%$ of the subjects, “Good” among 29.55\%, “Acceptable” among 18.75\%, and "Poor” among 3.98\%.

\section{Discussion}

Stable angina represents the initial clinical picture of ischemic heart disease in $50 \%$ of affected patients [18]. Alone, angina pectoris as a clinical entity presents a negative impact on patient quality of life [2] [19]. Although

Table 1. Demographic data and pretreatment characteristics.

\begin{tabular}{|c|c|c|}
\hline Variable & Result (n) & Result (\%) \\
\hline \multicolumn{3}{|l|}{ Ethnicity (n) } \\
\hline Asian & 2 & 1 \\
\hline Black & 47 & 23.5 \\
\hline Caucasian & 78 & 39 \\
\hline Mulatto & 73 & 36.5 \\
\hline Height (cm) & $167.1( \pm 9.48)$ & \\
\hline \multicolumn{3}{|l|}{ General nutrition } \\
\hline Good & 90 & 45 \\
\hline Moderate & 91 & 45.5 \\
\hline Poor & 19 & 9.5 \\
\hline \multicolumn{3}{|l|}{ Alcohol consumption } \\
\hline None & 99 & 49.5 \\
\hline Moderate ( $<2$ drinks/week) & 90 & 45 \\
\hline Heavy ( $\geq 2$ drinks/week) & 11 & 5.5 \\
\hline \multicolumn{3}{|l|}{ Smoking } \\
\hline Non-smoker & 67 & 33.5 \\
\hline$<10$ cigarettes/day & 60 & 30 \\
\hline$\geq 10$ cigarettes/day & 73 & 36.5 \\
\hline \multicolumn{3}{|l|}{ Manual labor } \\
\hline Light & 92 & 46 \\
\hline Moderate & 77 & 38.5 \\
\hline Heavy & 31 & 15.5 \\
\hline \multicolumn{3}{|l|}{ Sports/Exercise } \\
\hline None & 115 & 57.5 \\
\hline Irregular & 77 & 38.5 \\
\hline Regular (at least 1×/week) & 8 & 4 \\
\hline
\end{tabular}

Table 2. Vital signs and physical exam results.

\begin{tabular}{ccccc}
\hline Observation & Pretreatment & Visit 2 & Visit 3 & Change during treatment period \\
\hline Weight $(\mathrm{kg})$ & $72.8( \pm 11.91)$. & $73.17( \pm 12.11)$ & $73.11( \pm 12.00)$ & $\mathrm{p}=0.342$ \\
BMI $\left(\mathrm{kg} / \mathrm{cm}^{2}\right)$ & $25.97( \pm 3.062)$ & $26.10( \pm 3.10)$ & $26,03( \pm 3.102)$ & $\mathrm{p}=0.008$ \\
Systolic blood pressure $(\mathrm{mmHg})$ & $133.4( \pm 10.85)$ & $129.1( \pm 7.37)$ & $128.3( \pm 7.24)$ & $\mathrm{p}<0.0001$ \\
Diastolic blood pressure $(\mathrm{mmHg})$ & $86.53( \pm 8.84)$ & $84.16( \pm 6.9)$ & $83.87( \pm 6.81)$ & $\mathrm{p}<0.0001$ \\
Heart rate $(\mathrm{bpm})$ & $69.60( \pm 4.52)$ & $68.22( \pm 5.55)$ & $67.91( \pm 5.12)$ & $\mathrm{p}=0.0001$ \\
Respiratory rate $(\mathrm{ipm})$ & $15.77( \pm 2.07)$ & $15.67( \pm 1.97)$ & $16.04( \pm 4.32)$ & $\mathrm{p}=0.23$ \\
\hline
\end{tabular}

Data are mean $( \pm \mathrm{SD})$. 


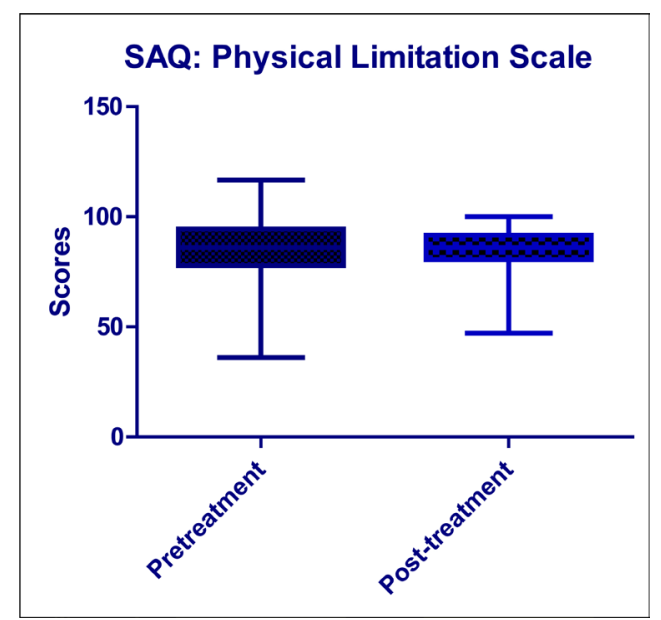

(a)

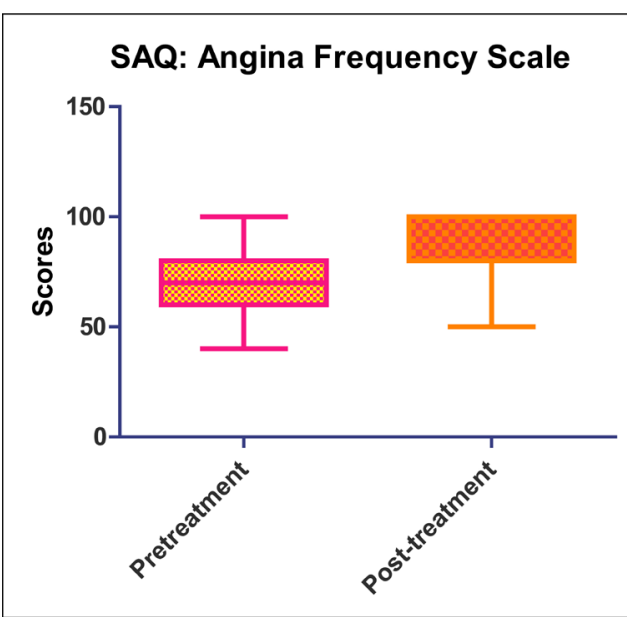

(c)

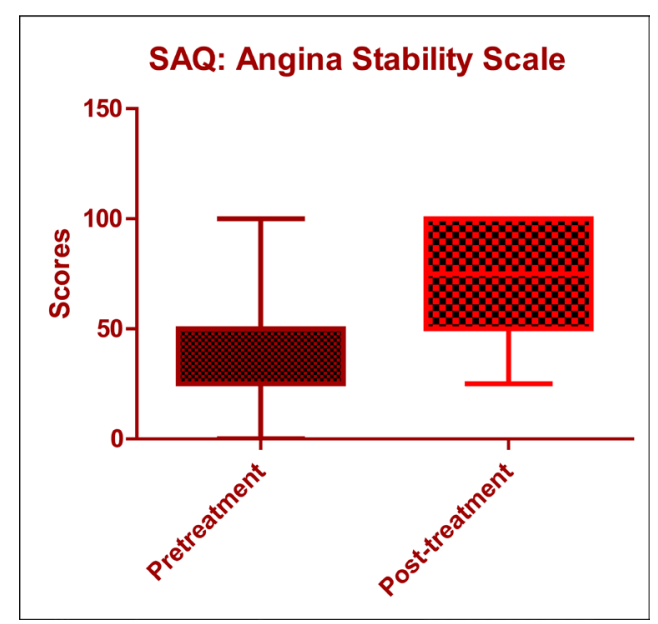

(b)

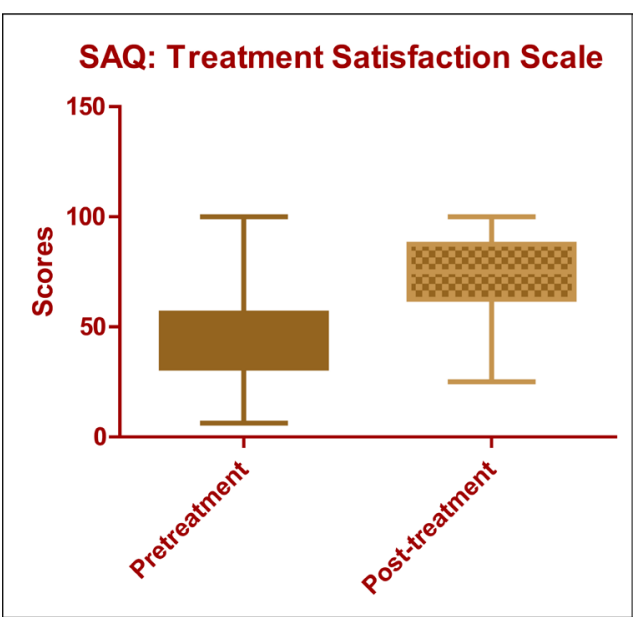

(d)

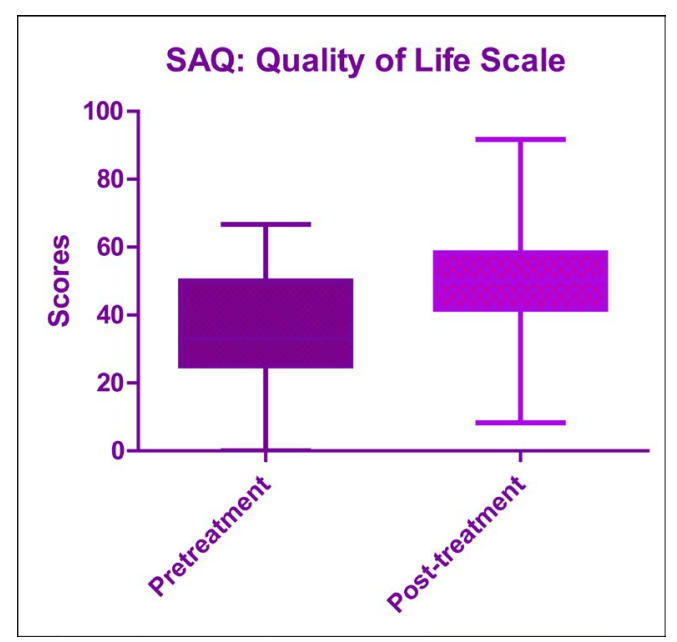

(e)

Figure 1. (a) Physical Limitation Scale. No significant difference between Pre- and Post-Treatment assessments (p = 0.7415); (b) Angina Stability Scale; (c) Angina Frequency Scale. Statistically significant improvement at Post-Treatment compared to Pretreatment values ( $<$ 0.0001); (d) Treatment Satisfaction Scale. Statistically significant improvement at Post-Treatment compared to Pretreatment values ( $<0.0001)$; (e) Quality of Life Scale. Statistically significant improvement at Post-Treatment compared to Pretreatment values $(\mathrm{p}<0.0001)$. 
this study presents the limitation of no placebo control group (for ethical reasons), the results of this study indicate a favorable impact of propatyl nitrate therapy on quality of life among patients presenting with chronic stable angina. Indeed, treatment with propatyl nitrate yielded favorable, statistically significant improvements in each of the SAQ scales, with the exception of Physical Limitation, where improvement did not reach statistical significance. This result may be due to the treatment group not having presented a great deal of physical limitation to begin with; pretreatment mean scores for this subcategory were 85.06 compared to post-treatment scores of 85.48 .

Efficacy of the nitrates and nitrites as vasodilators has been extensively reported and documented in the literature [11] [13] and the findings of this study are in agreement with those previously reported for propatyl nitrate use in terms of number of angina episodes [15] [20]. Given the fact that previous studies of propatyl nitrate were performed in the 1960s and did not employ the SAQ, it is difficult to perform a comparative analysis with the results of our study [11]-[15] [20]. Furthermore, most of these studies induced acute angina pectoris using the exercise-tolerance test while our study assessed subjects as they carried our normal daily activities.

Overall, propatyl nitrate was well-tolerated, with no occurrence of serious adverse events. Adverse events that were observed were for the most part mild in severity and transient in duration, resolving prior to the end of the treatment period. The adverse events observed during the treatment period were in accordance with those reported in the literature associated with nitrate therapy, including headache, dizziness, and gastrointestinal side effects [21]. Treated subjects did have increase in BMI, and reduction in heart rate and blood pressure (as expected when using nitrates) while remaining safety variables were unchanged. Laboratory and electrocardiogram results did not vary throughout the treatment period.

In Brazil, propatyl nitrate is among the most commonly employed medications for the treatment of stable angina pectoris [1]. Nitrates represent the oldest treatment modality for addressing angina pectoris [21]. Although this drug has been in use for over 60 years, there is little data in the national and international literature on its use among patients with chronic stable angina pectoris. It is hoped that the results of this study will contribute to the knowledge of the effect of propatyl nitrate on this patient population.

\section{Conclusion}

The results of this study indicate that therapy with propatyl nitrate was safe and effective in treating chronic stable angina pectoris over the course of the 30-day treatment period. Treatment with propatyl nitrate increased angina stability and reduced angina frequency while increasing treatment satisfaction and quality of life in the patient population evaluated.

\section{Acknowledgements}

The authors thank Renata K. Ribeiro Coutinho and Flavia Dweck for help with data collection, Aline Pacheco M. da Silva and Mario Nilo Paulain Cavalcante for study monitoring, and Prof. Oscar Roberto Guimarães for help with laboratory analyses.

\section{References}

[1] Cesar, L.A.M., Mansur, A.P., Armaganijan, D., et al. (2004) Diretrizes de doença coronária crônica angina estável. Arquivos Brasileiros de Cardiologia, 83, 2-43. http://dx.doi.org/10.1590/S0066-782X2004002100001

[2] Go, A.S., Mozaffarian, D., Roger, V.L., et al. (2013) Heart Disease and Stroke Statistics—2013 Update: A Report from the American Heart Association. Circulation, 127, e6-245. http://dx.doi.org/10.1161/CIR.0b013e31828124ad

[3] Fihn, S.D., Gardin, J.M., Abrams, J., et al. (2012) American College of Cardiology Foundation/American Heart Association Task Force. 2012 ACCF/AHA/ACP/AATS/PCNA/SCAI/STS Guideline for the Diagnosis and Management of Patients with Stable Ischemic Heart Disease: A Report of the American College of Cardiology Foundation/American Heart Association Task Force on Practice Guidelines, and the American College of Physicians, American Association for Thoracic Surgery, Preventive Cardiovascular Nurses Association, Society for Cardiovascular Angiography and Interventions, and Society of Thoracic Surgeons. Circulation, 126, e354-471. http://dx.doi.org/10.1161/CIR.0b013e318277d6a0

[4] Beltrame, J.F.M., Weekes, A.J., Morgan, C., Tavella, R. and Spertus, J.A. (2009) The Prevalence of Weekly Angina in Primary Care Practices: The Coronary Artery Disease in General Practice (CADENCE) Study. Archives of Internal Medicine, 169, 1491-1499. http://dx.doi.org/10.1001/archinternmed.2009.295 
[5] Brorsson, B., Bernstein, S.J., Brook, R.H. and Werkö, L. (2002) Quality of Life in Patients with Chronic Stable Angina before and Four Years after Coronary Revascularisation Compared with a Normal Population. Heart, 87, 140-145. http://dx.doi.org/10.1136/heart.87.2.140

[6] Javitz, H.S., Ward, M.M., Watson, J.B. and Jaana, M. (2004) Cost of Illness of Chronic Angina. American Journal of Managed Care, 10, S358-369.

[7] Armaganijan, D., Batlouni, M., Ghorayeb, N., Dioguardi, G.S. and Ogawa, C. (1980) Avaliação cicloergométrica do propatilnitrato na insuficiência coronária crônica. Arquivos Brasileiros de Cardiologia, 34, 73-77.

[8] Castro, I., Rocha, G., Guimarães, B.E. and Rodrigues, R. (1983) Avaliação dos efeitos do propatilnitrato em pacientes cardiopatas isquêmicos através da cicloergonometria. Farmacias F-Medica, 86, 0279-0283.

[9] Manfroi, W.C., Koppe, V., Vieira, S.R., et al. (1987) Efeitos hemodinâmicos e cineangiográficos agudos do propatilnitrato na cardiopatia isquêmica sintomática. Arquivos Brasileiros de Cardiologia, 48, 0147-0151.

[10] Savioli, M.R., Lima, E.V., Frederico, W.A., et al. (1983) Cineventriculografia radioisotópica durante exercício físico em portadores de coronariopatia. Avaliação dos efeitos do propatilnitrato. Arquivos Brasileiros de Cardiologia, 41, 77-83.

[11] Johnsson, G., Henning, M. and Ablad, B. (1965) Rate of Vasodilator Effect of Glyceryl Trinitrate, Propatylnitrate and Erythrityl Tetranitrate in Man. Scandinavian Journal of Clinical and Laboratory Investigation, 17, 0600-0606. http://dx.doi.org/10.3109/00365516509083369

[12] Oram, S. and Sowton, E. (1961) Failure of Propatylnitrate and Pentaerythritol Tetranitrate to Prevent Attacks of Angina Pectoris. British Medical Journal, 2, 1745-1746. http://dx.doi.org/10.1136/bmj.2.5269.1745

[13] Sandler, G. (1961) Clinical Evaluation of Propatylnitrate in Angina Pectoris. British Medical Journal, 2, $1741-1744$. http://dx.doi.org/10.1136/bmj.2.5269.1741

[14] Oga, S. and Hanada, S. (1980) Parametros cardiovasculares e biodisponibilidade de nitrato de isorbitol, nifedipina e propatilnitrato. Farmacias F-Medica, 80, 895-898.

[15] Santana, R.F., Godoy, M., Mantovanini, J.A., et al. (1988) Avaliação de nitrato de ação rápida através de dados clínicos e teste de esforço. Farmacias F-Medica, 97, 341-345.

[16] Canadian Cardiovascular Society Website. http://www.ccs.ca

[17] Spertus, J.A., Winder, J.A., Dewhurst, T.A., et al. (1995) Development and Evaluation of the Seattle Angina Questionnaire: A New Functional Status Measure for Coronary Artery Disease. Journal of the American College of Cardiology, 25, 333-341. http://dx.doi.org/10.1016/0735-1097(94)00397-9

[18] Atmakuri, S.R., Gollob, M.H. and Kleiman, N.S. (2005) Stable Angina. In: Rosendorff, C., Ed., Essential Cardiology: Principles and Practice, 2nd Edition, Humana Press, Totowa, 451-470.

[19] Pragodpol, P. and Ryan, C. (2013) Critical Review of Factors Predicting Health-Related Quality of Life in Newly Diagnosed Coronary Artery Disease Patients. Journal of Cardiovascular Nursing, 28, 277-284. http://dx.doi.org/10.1097/JCN.0b013e31824af56e

[20] Nordqvist, P. and Varnauskas, E. (1960) [Ettriol Trinatrate-A New Nitrate Compound]. Svenska Läkartidningen, 57, 2173-2181.

[21] Boden, W.E., Finn, A.V., Patel, D., Peacock, W.F., Thadani, U. and Zimmerman, F.H. (2012) Nitrates as an Integral Part of Optimal Medical Therapy and Cardiac Rehabilitation for Stable Angina: Review of Current Concepts and Therapeutics. Clinical Cardiology, 35, 263-271. http://dx.doi.org/10.1002/clc.21993 


\section{Submit or recommend next manuscript to SCIRP and we will provide best service for you:}

Accepting pre-submission inquiries through Email, Facebook, LinkedIn, Twitter, etc.

A wide selection of journals (inclusive of 9 subjects, more than 200 journals)

Providing 24-hour high-quality service

User-friendly online submission system

Fair and swift peer-review system

Efficient typesetting and proofreading procedure

Display of the result of downloads and visits, as well as the number of cited articles

Maximum dissemination of your research work

Submit your manuscript at: http://papersubmission.scirp.org/ 